\title{
The Sharing-Exchange Continuum Inside of the Sharing Economy
}

\author{
Philipp Lee, Michael J. Kendzia* \\ Zurich University of Applied Sciences, Winterthur, Switzerland \\ Email: *kend@zhaw.ch
}

How to cite this paper: Lee, P., \& Kendzia, M. J. (2021). The Sharing-Exchange Continuum Inside of the Sharing Economy. American Journal of Industrial and Business Management, 11, 692-704. https://doi.org/10.4236/ajibm.2021.116045

Received: May 18, 2021

Accepted: June 25, 2021

Published: June 28, 2021

Copyright (c) 2021 by author(s) and Scientific Research Publishing Inc. This work is licensed under the Creative Commons Attribution International License (CC BY 4.0).

http://creativecommons.org/licenses/by/4.0/

\begin{abstract}
The sharing economy has been increasingly disrupting traditional business sectors and has put substantial pressure on firms in the global economy. The concept is per se nothing new. Resources that are not used are lent to individuals via an online platform in exchange for money or anything else. The idea of the sharing-exchange continuum suggests that in order to be successful, the business model has to include sharing as well as exchange attributes. This means that a company can simultaneously profit from the benefits of socialism (pure sharing) and capitalism (pure exchange). The findings from the case studies underpin the considered literature. Both Uber and Airbnb are located within the balanced sharing and exchange range of the sharing-exchange continuum. However, WeWork exhibits predominantly exchange characteristics but also tendencies towards more balanced attributes.
\end{abstract}

\section{Keywords}

Sharing Economy, Mesh Framework, Shareability

\section{Introduction}

Today's society is living in exciting and quickly changing times. In the last couple of years, various trends have emerged that provide society with unprecedented opportunities which might have a long-lasting impact.

The sharing economy has been increasingly disrupting traditional business sectors and has put substantial pressure on firms in the global economy (Munoz, 2017). The concept of the sharing economy is per se nothing new. Resources that are not used are lent to individuals via an online platform in exchange for money or anything else. The concept emerged from the financial crisis in 2008 and has ever since experienced a boom due to the rethinking of the relationship between the ownership of things and its relative value (Gansky, 2012). This has prompted 
businesses and consumers to develop ways to consume goods and services through sharing and pooling, in order to use resources that would otherwise be left idle (Habibi et al., 2017).

In research, the sharing economy has quickly become a popular subject (Dillahunt et al., 2017). Contributions made in the field have touched upon areas such as the emergence, managerial behavior, and business strategy in the sharing economy (Kumar, Lahiri, \& Dogan, 2017; Habibi et al., 2017; Basselier, Langenus, \& Walravens, 2018). However, current literature is far away from a universal definition and understanding of the sharing economy and its characteristics (Albinsson \& Perera, 2018).

Although earlier academic work has focused more on traditional sectors such as manufacturing (Hall \& Oriani, 2006), current research emphasizes more on the technology sector (Grennan \& Michaely, 2017; Bannigidadmath \& Narayan, 2016).

That said, this article seeks to shed light on the sharing-exchange continuum to quantify the extent of sharing involved in a transaction on a five-point scale. This is being done by the evaluation of various sharing- and exchange-related characteristics of three prominent companies representing the sharing economy.

To do so, the research article is structured in the following order: First, the concept and key hallmarks of the sharing economy based on existing theories are set out. Thereafter, the characteristics of the Sharing-Exchange Continuum are defined, which are used as theoretical framework to compare and analyze various dimensions of already successful firms in the disruptive economy.

\section{Theoretical Framework}

In the following section, previous research, terminologies as well as relevant models are introduced regarding the sharing economy. It allows to gather existing information and provide an understanding of previously issued debates. Further, emerging markets are estimated to grow at a higher rate compared to mature markets and thus, provide further growth potential for the sharing economy (Wallenstein \& Shelat, 2017).

\subsection{The Sharing Economy}

The concept of the sharing economy is per se nothing new (Albinsson \& Perera, 2018). A glance at the evolution of economic activities reveals that prior to the Industrial Revolution, a significant percentage of the exchange of goods and services was already peer-to-peer embedded and intertwined in different ways with social relations (Sundararajan, 2016). Similar to that, today's sharing economy emerges from the fact that people exchange underutilized assets in the form of goods and services with others in the market through an online-based application.

Figure 1 illustrates the concept of the sharing economy. The online platform, provided by the firm in the sharing economy, connects the owner of an asset or service with the respective seeker. While the owner receives in return for sharing 


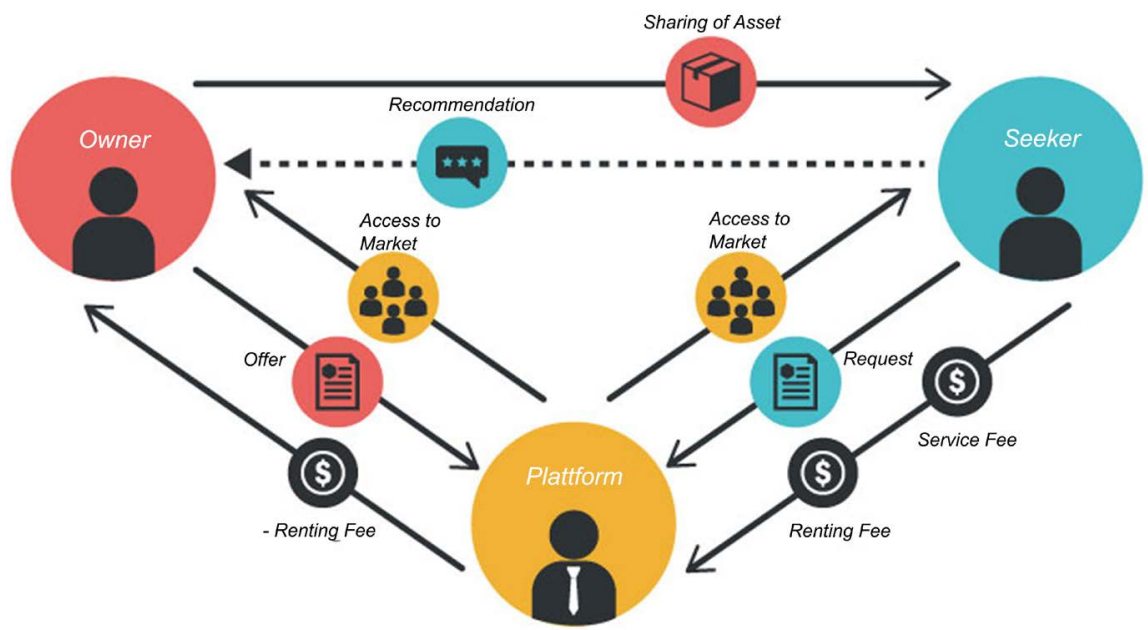

Figure 1. Concept of the sharing economy. Source: Business Model Toolbox (n.d.). Note: With the authorization of Business Model Toolbox.

a renting fee from the seeker, the sharing platform keeps a service commission that is additionally paid by the seeker (Kumar et al., 2017). Overall, the sharing economy platform acts as an intermediary between the owner and seeker. It merely provides access to the market while matching offers from the owner and requests from the seeker (Gansky, 2012).

In Figure 1 the owner of a certain asset or service submits an offer, including its renting or service fee, such as for instance the apartment or car ride. The platform operates like a hub and provides access for both the owner and seeker of the renting or service. Following this, potential seekers or customers send their request and indicate their interest. An additional feature is that former customers can provide feedback for the owner or rather future customers by giving recommendations.

Despite the above-described concept, there is no consensus on a definition of the sharing economy (Sundararajan, 2016). However, a possible interpretation of the sharing economy was described by Lisa Gansky (2012), which entails five characteristics.

\begin{tabular}{ll}
\hline Shareability: & $\begin{array}{l}\text { Products and services can be shared within a community or market, } \\
\text { which can be local or global. }\end{array}$ \\
The sharing economy relies heavily on advanced digital networks. & $\begin{array}{l}\text { Thed digital networks. } \\
\text { Data gathered from the exchange regarding the parties involved, } \\
\text { and the product can be traced in real time. }\end{array}$ \\
& $\begin{array}{l}\text { Users of the sharing economy can access shared goods and services } \\
\text { at their physical location. }\end{array}$ \\
Immediacy: & $\begin{array}{l}\text { Advertising of the product is replaced with promotions that are } \\
\text { driven by social media platforms. }\end{array}$ \\
Social media driven & $\begin{array}{l}\text { The sharing economy can be scaled globally and has high potential. } \\
\text { Global in scale and potential: }\end{array}$
\end{tabular}

\subsection{The Sharing-Exchange Continuum}

The sharing-exchange continuum, as illustrated in Figure 2, enables to quantify 


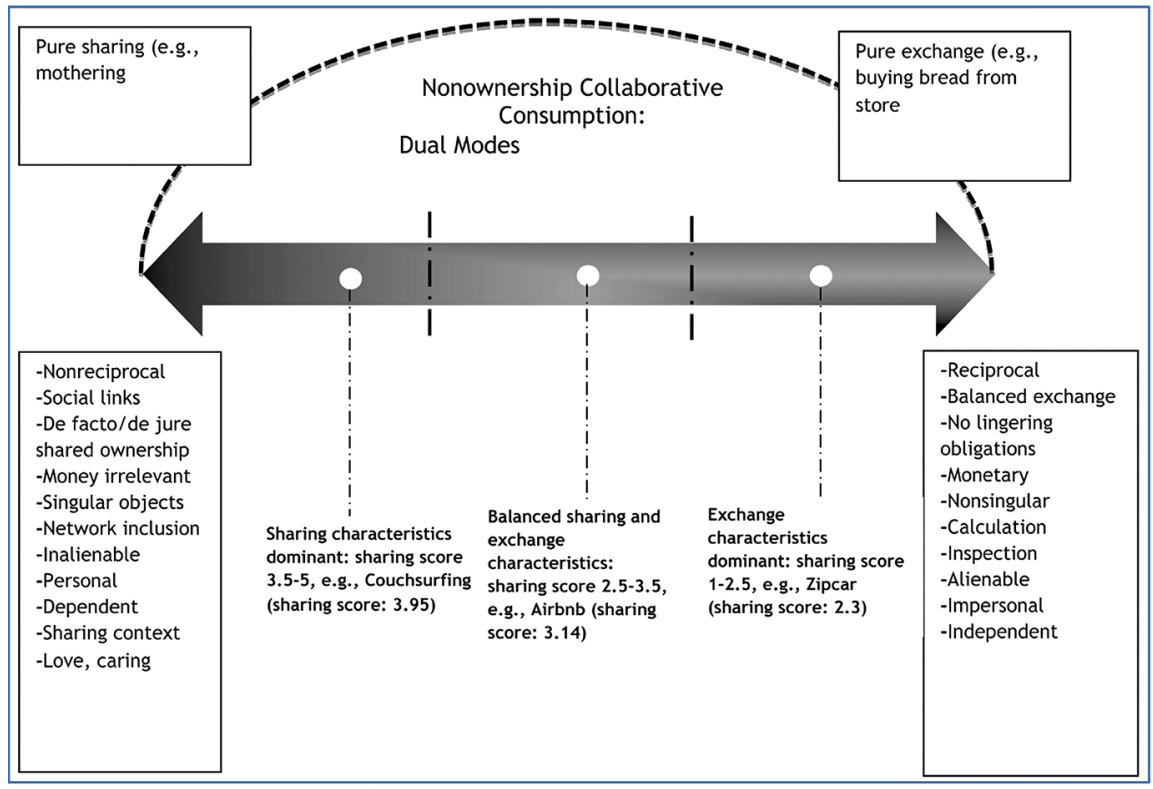

Figure 2. The sharing-exchange continuum. Source: Habibi et al. (2017).

the extent of sharing involved in a transaction on a five-point scale (Habibi et al., 2017).

This is done by the evaluation of various sharing- and exchange-related characteristics, located on the bottom left and right of Figure 2. The calculated sharing score, based on the average of each characteristic, enables to observe where a firm's practice falls on the continuum, compared to other businesses. A detailed description of the various characteristics of sharing versus exchange can be found in Table 1 .

A score to the left of the continuum (sharing score 5) indicates a pure sharing business model, whereas businesses located to the far right (sharing score 1) are focusing on pure exchange.

As claimed by Habibi et al. (2017), the categorization of firms within the sharing-exchange continuum can provide managers with recommendations on how to further develop a company's strategy. A summary of possible recommendations can be found in Appendix A. Within the scope of this article, the first four characteristics are analyzed, which are considered the most important ones.

\subsection{The Mesh Model}

Lisa Gansky (2012) developed a framework that allows assessing the suitability of a product or service for the sharing economy. The author referred to the optimal product for the sharing economy as the mesh sweet spot. As shown in Figure 3, a product or service can be grouped into four categories based on the evaluation of its cost or monetary value ( $x$-axis) and its frequency of use (y-axis). Based on this framework, products and services of a company operating within the sharing economy most likely succeed if they are highly valuable but infrequently used. 
Table 1. Characteristics of sharing versus exchange.

\begin{tabular}{|c|c|c|}
\hline Sharing & Exchange & Description \\
\hline Nonreciprocal & Reciprocal & $\begin{array}{l}\text { Reciprocation is not expected in sharing, but it is } \\
\text { an important element of exchange }\end{array}$ \\
\hline Social bonds & No social bonds & $\begin{array}{l}\text { Sharing creates some sort of social bonds, but } \\
\text { this is not necessarily the case in exchange }\end{array}$ \\
\hline Joint ownership & No joint ownership & $\begin{array}{l}\text { In sharing both parties feel responsible toward } \\
\text { the object being used (feelings of joint ownership) } \\
\text { but this is not the case in exchange }\end{array}$ \\
\hline Money irrelevant & Money relevant & $\begin{array}{l}\text { Sharing does not require transfer of money, but } \\
\text { exchange does }\end{array}$ \\
\hline Dependent & Independent & $\begin{array}{l}\text { Consumption through sharing depends on other } \\
\text { people involved but exchange is independent }\end{array}$ \\
\hline Similarity to real sharing & Similarity to exchange & - \\
\hline Social reproduction & $\begin{array}{l}\text { Lack of social } \\
\text { reproduction }\end{array}$ & $\begin{array}{l}\text { Sharing produces social capital and links, } \\
\text { exchange usually does not }\end{array}$ \\
\hline Singular & Nonsingular & Objects are singular in sharing but not in exchange \\
\hline Money not important & Money important & $\begin{array}{l}\text { Money is important in exchange but there is a } \\
\text { lack of money exchange in sharing }\end{array}$ \\
\hline Lack of calculation & Calculation & Precise calculation is a property of exchange \\
\hline
\end{tabular}

Source: Own illustration based on Belk $(2007,2009)$.

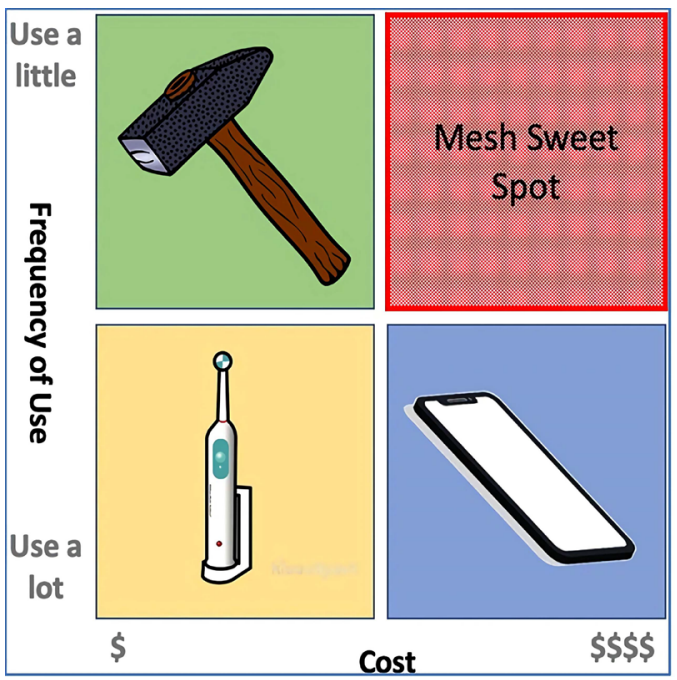

Figure 3. The mesh framework. Source: Own illustration based on Gansky (2012).

In detail this means that the electronic tooth brush as a frequently used and affordable device does not pose a suitable product for the sharing economy. The same holds true for a tool such as a hammer. The tool poses an affordable, but at the same time not very frequently used product. Given the low prices of both products, they are unlikely to be shared amongst individuals.

In case of a smartphone, however, despite its high price, the frequent use of the electronic device makes it also inappropriate for sharing. The three selected 
companies nevertheless, sharing cars, apartments or houses as well as offices meet the criteria of highly valuable products that are infrequently used and can be located within the Mesh Sweet Spot.

However, products and services that are not located within the Mesh Sweet Spot are not necessarily considered to be non-shareable. Merely, it indicates that the market for sharing the particular item might not be as promising (Gansky, 2012). However, as all investigated companies meet the criterion of the Mesh Sweet Spot, the Mesh Model will not further be taken into consideration. Instead, this article focuses solely on the Sharing-Exchange Continuum.

\section{Methodological Approach}

The article primarily used secondary research from academia and industry, which represents the status-quo of current knowledge. Furthermore, case studies were used in order to compare and analyze multiple established firms in the sharing economy.

In general, constructing a theory from case studies is a common research strategy which uses one or more cases to create a theoretical framework, propositions, case-based theories or empirical evidence (Eisenhardt, 1989). Further, they are a useful tool to analyze a particular phenomenon in research (Bryan \& Bell, 2007; Yin, 2009).

This inductive research method is often used to generate a data set in order to identify patterns and relationships that can be used to build a new theory or framework within a discipline of research (Adams et al., 2007).

Within this work, a single case studies structure was used in order to compare and analyze various dimensions of already successful firms in the disruptive economy. For the case studies, three companies within the sharing economy were chosen. The criteria chosen were based on the nature of the subject as well as the literature reviewed.

The criteria are the following: 1) The company has a major impact on people's daily life. 2) The organization has an established business at work. 3) The companies are not direct competitors. Based on the criteria described above, the firms Uber Technologies, Inc., Airbnb, Inc., and The We Company were chosen.

\section{Findings}

\subsection{Case Study I: Uber Technologies, Inc.}

The business model of the company is relatively simple. The web application operates in the intersection of lifestyle and logistics by providing a two-sided marketplace for buyer and sellers. As a consequence of providing an onlinebased platform, Uber was supposed to own no inventory, warehouses, distribution centers or the like and therefore, generate almost no overheads (Lashinsky, 2017).

The value-added for the company's customers comes in multiple forms. Firstly, 
the company screens its customers in order to ensure a certain quality, safety and comfort. Secondly, the app-integrated payments system, which is connected to a credit card facilitates the process for all involved parties as no physical money is exchanged (Schneider, 2017).

Lastly, customers looking for a ride can choose the level of service, which is based on the type of car ranging from ordinary cars, SUVs to limousines. Depending on the service level chosen, customers pay a higher rate, which is divided into a fixed and flexible fare component, which depends on time and distance.

Furthermore, prices are based on the basic economic principle of demand and supply, indicating a premium price for rides during peak demand times (Uber, n.d.-a; Uber, n.d.-b).

Uber also handles the payment for drivers and customers through its own platform. The company generates revenues by keeping around $20 \%$ of the total ride value, which depicts an all-in intermediation fee (Schneider, 2017).

In the last years, Uber's service offering has gone beyond matching demand and supply for rides. UberEATS, an online food ordering and delivery platform was launched in 2014. The service provides opportunities for restaurants to gain access to customers willing to order food. Private drivers are then delivering the ordered food to the customers (Uber Eats, n.d.-c).

\section{Sharing-Exchange Continuum}

The following section assesses Uber regarding the sharing-exchange continuum in order to determine the degree of sharing involved in the business transaction.

Nonreciprocal vs. Reciprocal (Score: 2): Alike ordering a taxi, the hierarchy between the service consumer (guest) and provider (driver) is reasonably clear. The driver aims to provide the most comfortable service possible. The customer on the other hand, has almost no specific obligation towards the driver. Therefore, there is per se no compelling reciprocal activity between consumer and provider. However, social interaction between drivers and guests is an integral part of Uber's vision (Uber, 2019). Thus, guests often feel obliged to have a conversation with the driver in order to create a mutually pleasant atmosphere, which can be perceived to be reciprocal.

Social Links vs. Balanced Exchange (3): The creation of social bonds during a ride is almost inevitable as drivers and guests interact with each other. However, due to the fact that interaction is not required and depend on various situational factors, the degree of social links is to some extent, limited.

De Facto Ownership vs. No Lingering Obligations (3): In case the of sharing a ride, both parties feel responsible for taking care of the car being used. Nevertheless, the feeling of responsibility is much higher with the driver due to the fact of the possession of the vehicle itself. At the same time, guests are expected to behave responsibly while being driven to the destination.

Money Irrelevant vs. Monetary (4): Uber's concept is based on the exchange of money for the service of driving one to its destination. However, as men- 
tioned before the social exchange and interaction between all participants during an Uber ride is higher compared to a taxi ride, which might be one of the reasons why people prefer Uber.

Based on the evaluation in Table 2, Uber's score within the sharing-exchange continuum is three. Thus, the concept of the company is based on balanced sharing and exchange characteristics (Score: 2.5 - 3.5).

\subsection{Case Study II: Airbnb, Inc.}

Airbnb is a web-based platform for individuals who want to rent their rooms to travelers. Thus, the company's business concept connects consumers (travelers) and providers (hosts) for listing and renting local homes (Gallagher, 2017). A typical consumer on Airbnb seeks the experience to live like a local, which hotels generally cannot provide. Renters, on the other side, want to supplement their income by renting out vacant rooms and beds (Airbnb, n.d.).

The company takes a commission, known as the service fee from travelers and hosts alike. For travelers, Airbnb charges a fee ranging from six to twelve percent, depending on the subtotal of the entire rent. Thus, the higher the total booking amount, the lower is the fee. The host, providing accommodation pays a three percent fee, which is intended to cover the cost of payment transfer of Airbnb (Gallagher, 2017).

\section{Sharing-Exchange Continuum}

The following section assesses Airbnb regarding the sharing-exchange continuum in order to evaluate the degree of sharing involved in the business transaction.

Nonreciprocal vs. Reciprocal (Score: 3): When it comes to the evaluation of reciprocity, which means the return of a possible favor for the service provided, it needs to be distinguished between two types of Airbnb rentals.

In case a guest rents an entire apartment, there is almost no reciprocal action, due to the fact that there is no to little personal interaction with the host. However, if only a spare room is rent, which is the initial concept of the company, the potential of reciprocity is comparably high as hosts and guests inevitably interact and benefit from each other.

Social Links vs. Balanced Exchange (Score: 3): Similar to the evaluation of reciprocity, social links between hosts and guests depend on the type of apartment rent. Even though guests can have their privacy within their room, interaction with others is inevitable.

Table 2. Sharing-exchange continuum score: Uber.

\begin{tabular}{cc}
\hline Dimension (sharing vs. exchange) & Rating (1 - 5) \\
\hline Nonreciprocal vs. Reciprocal & 2.0 \\
Social Links vs. Balanced Exchange & 3.0 \\
De Facto Ownership vs. No Lingering Obligations & 3.0 \\
Money Irrelevant vs. Monetary & 4.0 \\
Average Total Score & 3.0 \\
\hline
\end{tabular}


De Facto Ownership vs. No Lingering Obligations (Score: 2): With the concept of Airbnb, hosts and guests have the responsibility towards the apartment. Guests, however, feel probably even more responsible compared to sharing other objects such as a car.

This might stem from the fact that the effect of possible irresponsible actions such as, not keeping the room clean, have a longer negative effect on themselves.

Money Irrelevant vs. Monetary (Score: 4): Airbnb's concept of sharing a room or an entire apartment is based on the exchange of money for service concept. However, social interaction might be a factor that leads people to prefer Airbnb over a hotel.

Based on the evaluation in Table 3, Airbnb's score within the sharing-exchange continuum is three. Thus, the concept of the company is based on balanced sharing and exchange characteristics (Score: 2.5 - 3.5).

\subsection{Case Study III: The We Company (WeWork)}

The business model of WeWork entails renting space in large buildings itself, converting it into smaller offices, and licensing these units or single desks to people in the market. Per se, the company does not own any of the buildings it rents to its tenants. Thus, WeWork is not directly exposed to significant risks related to owning real estate, such as falling prices or high maintenance costs (Levine, 2019).

\section{Sharing-Exchange Continuum}

The following section assesses WeWork regarding the sharing-exchange continuum in order to determine the degree of sharing involved in the business transaction.

Nonreciprocal vs. Reciprocal (Score: 2): Reciprocity, the principle of returning a favor to the one providing goods or services is not directly expected with WeWork.

However, one of the benefits of shared office spaces is the possibility to interact with other customers. This social as well as knowledge exchange, is not only encouraged by WeWork but also expected. Thus, reciprocity is only indirectly expected.

Social Links vs. Balanced Exchange (Score: 3): Due to the fact that people work in facilities of WeWork and share common space, the emergence of social links is likely. The degree of social links might depend on various factors such as

Table 3. Sharing-exchange continuum score: Airbnb.

\begin{tabular}{cc}
\hline Dimension (sharing vs. exchange) & Rating (1 - 5) \\
\hline Nonreciprocal vs. Reciprocal & 3 \\
Social Links vs. Balanced Exchange & 3 \\
De Facto Ownership vs. No Lingering Obligations & 2 \\
Money Irrelevant vs. Monetary & 4 \\
Average Total Score & 3.0
\end{tabular}


the type of office space rent (shared vs. private) and the personal behavior of customers working in the WeWork facilities.

De Facto Ownership vs. No Lingering Obligations (Score: 2): The shared feeling of responsibility towards the office space is somewhat limited to WeWork as well as its tenants. This stems from the fact that the company per se is also merely a tenant. Yet, both parties are endeavored to use the space responsibly. While WeWork is interested in keeping its property lease, customers are interested in creating and keeping a comfortable working environment.

Money Irrelevant vs. Monetary (Score: 2 ): The exchange activity within the WeWork concept is highly based on monetary incentives. The company basically acts as a middleman, transferring larger leasing space into smaller office spaces (Levine, 2019).

Therefore, the financial benefits for the company are a key component of the company's business model and do not entail any sharing components from a provider and consumer perspective.

Based on the evaluation in Table 4, WeWork's score within the sharing-exchange continuum is two. Thus, the concept of the company is more based on exchange characteristics (Score: 1.0 - 2.5).

\section{Discussion}

As stated in secondary literature, many firms consider themselves as part of the disruptive economy. However, some companies do not demonstrate many characteristics that are considered to be critical to the sharing economy.

The concept of the sharing-exchange continuum suggests that in order for a company to be successful, the business model has to include sharing as well as exchange attributes. This means that a company can simultaneously profit from the benefits of socialism (pure sharing) and capitalism (pure exchange).

Generally, the findings from the case studies underpin the considered literature. Uber, as well as Airbnb, are located within the balanced sharing and exchange range of the sharing-exchange continuum. However, WeWork exhibits exchange characteristics predominantly but also tendencies towards more balanced attributes.

It is vital for firms to be perceived as part of the sharing economy while simultaneously focus on profits. The trend of more sustainable and social consumption

Table 4. Sharing-exchange continuum score: The We Company.

\begin{tabular}{cc}
\hline Dimension (sharing vs. exchange) & Rating (1 - 5) \\
\hline Nonreciprocal vs. Reciprocal & 2 \\
Social Links vs. Balanced Exchange & 3 \\
De Facto Ownership vs. No Lingering Obligations & 2 \\
Money Irrelevant vs. Monetary & 1 \\
Average Total Score & $\mathbf{2 . 0}$ \\
\hline
\end{tabular}


has gained increasing popularity in recent years. Therefore, companies have to exploit the opportunity of sharing in order to become successful and economically profitable.

\section{Conclusion}

The concept is not only disrupting traditional industries such as the transportation sector with firms like Uber, but also transforming the general perception of consumption in society. Furthermore, an increasing number of firms in the sharing economy have made efforts to go public and offer their shares at the stock exchange.

The analysis of this article regarding the areas of the sharing economy and investing is subject to a number of limitations, which will be addressed in this chapter. Firstly, one company is still privately-owned, which led to a lack of publicly available date. Some of the data used was based on research from industry experts. To minimize possible biased data, multiple secondary sources were considered in order to ensure a reliable data basis.

Secondly, the analysis has been mutually exclusive with regard to certain areas of the sharing economy and investing due to the extensive research gap. Thus, the exploratory approach was not exhaustive and did not include all relevant dimensions.

The sharing economy is currently predominantly disrupting distinct traditional industries such as transportation, lodging and real estate. More industries are affected but not to the same degree. However, it is expected that an increasing amount of companies will promote the concept of sharing in multiple other industries.

This article provides many opportunities for future research in the area of the sharing economy. Further research may also be done regarding investment in the sharing economy from a venture capital and private equity perspective. This would provide an insight in the decision-making process of institutional investors.

\section{Conflicts of Interest}

The authors declare no conflicts of interest regarding the publication of this paper.

\section{References}

Adams, J., Khan, H. T., Raeside, R., \& White, D. (2007). Research Methods for Graduate Business and Social Science Students. New Delhi: SAGE Publications.

Airbnb (n.d.). Financials. https://www.airbnb.com/b/financials

Albinsson, P. A., \& Perera, Y. B. (2018). The Rise of the Sharing Economy. Santa Barbara, CA: Praeger.

Bannigidadmath, D., \& Narayan, P. K. (2016). Stock Return Predictability and Determinants of Predictability and Profits. Emerging Markets Review, 26, 153-173.

https://doi.org/10.1016/j.ememar.2015.12.003 
Basselier, R., Langenus, G., \& Walravens, L. (2018). The Rise of the Sharing Economy. Economic Review, No. 3, 57-78.

Belk, R. (2007). Why Not Share Rather than Own? The Annals of the American Academy of Political and Social Science, 611, 126-140. https://doi.org/10.1177/0002716206298483

Belk, R. (2009). Sharing. Journal of Consumer Research, 36, 715-734. https://doi.org/10.1086/612649

Bryan, A., \& Bell, E. (2007). Business Research Methods. In A. Bryan, \& E. Bell (Eds.), Business Research Methods (p. 806). Oxford: Oxford University Press.

Dillahunt, T. R., Wheeler, E., Cheng, H., Wang, X., Hecht, B., \& Zhu, H. (2017). The Sharing Economy in Computing: A Systematic Literature Review. PACM on Human-Computer Interaction, 1, 1-26. https://doi.org/10.1145/3134673

Eisenhardt, K. M. (1989). Building Theories from Case Study Research. Academy of Management Review, 14, 19. https://doi.org/10.2307/258557

Gallagher, L. (2017). The Hustle. In L. Gallagher (Ed.), The Airbnb Story: How Three Ordinary Guys Disrupted an Industry, Made Billions ... and Created Plenty of Controversy (pp. 6-81). Boston, MA: Houghton Mifflin Harcourt Publishing Company.

Gansky, L. (2012). The Mesh: Why the Future of Business Is Sharing. New York: Penguin Group.

Grennan, J., \& Michaely, R. (2017). FinTechs and the Market for Financial Analysis (p. 80). Irish Finance Working Paper Series Research Paper, 18-11.

Habibi et al. (2017). What Managers Should Know about the Sharing Economy. Business Horizons, 60, 113-121. https://doi.org/10.1016/j.bushor.2016.09.007

Hall, B. H., \& Oriani, R. (2006). Does the Market Value R\&D Investment by European Firms? Evidence from a Panel of Manufacturing Firms in France, Germany, and Italy. International Journal of Industrial Organization, 24, 971-993.

https://doi.org/10.1016/j.ijindorg.2005.12.001

Kumar et al. (2017). A Strategic Framework for a Profitable Business Model in the Sharing Economy. Industrial Marketing Management, 69, 147-160.

https://doi.org/10.1016/j.indmarman.2017.08.021

Lashinsky, A. (2017). Wild Ride: Inside Uber's Quest for Wold Domination. London: Penguin Random House.

Levine, M. (2019). Maybe WeWork Is Just a Real Estate Business. https://www.bloomberg.com/opinion/articles/2019-01-16/wework-ceo-adam-neumann -is-also-a-landlord

Munoz, P. (2017). Mapping out the Sharing Economy: A Configurational Approach to Sharing Business Modeling. Leeds: Elsevier. https://doi.org/10.1016/j.techfore.2017.03.035

Schneider, H. (2017). What Is Uber's Business Model? In H. Schneider (Ed.), Creative Destruction and the Sharing Economy: Uber as Disruptice Innovation (pp. 36-62). Cheltenham: Edward Elgar Publishing.

Sundararajan, A. (2016). The Sharing Economy. Cambridge: The MIT Press.

Uber (2019). Form S-1: Registration Statement: Uber Technologies, Inc. Washington DC: Unites States Security Exchange Commission.

Uber (n.d.-a). Always the Ride You Want. https://www.uber.com/ch/en/ride

Uber (n.d.-b). What We Offer. https://www.uber.com/en-CH/about/uber-offerings

Uber Eats. (n.d.-c). Discover Restaurants that Deliver Near You. 
https://www.ubereats.com/en-CH/

Wallenstein, J., \& Shelat, U. (2017). What's Next for the Sharing Economy. Berlin: The Boston Consulting Group.

Yin, R. K. (2009). Case Study Research: Design and Methods (Vol. 5). Thousand Oaks, CA: SAGE Publications, Inc.

\section{Appendices}

\section{Appendix A}

Summary of Recommendations to Managers in the Sharing Economy

\begin{tabular}{|c|c|c|c|}
\hline & $\begin{array}{l}\text { If you fall toward } \\
\text { the sharing side }\end{array}$ & If you fall in-between & $\begin{array}{l}\text { If you fall towards } \\
\text { the exchange side }\end{array}$ \\
\hline \multirow{2}{*}{ Sharing score } & $3.5-5$ & $2.5-3.5$ & $1-2.5$ \\
\hline & Sharing-practice & Dual-mode practice & Pseudo-sharing practice \\
\hline \multirow{2}{*}{ Recommendation 1} & Do not stop & Encourage & Deprioritize \\
\hline & community growth & community building & community building \\
\hline Recommendation 2 & $\begin{array}{l}\text { Emphasize } \\
\text { socialization }\end{array}$ & $\begin{array}{c}\text { Improve efficiency and } \\
\text { utilitarian value }\end{array}$ & $\begin{array}{l}\text { Emphasize efficiency and } \\
\text { utilitarian benefits }\end{array}$ \\
\hline Recommendation 3 & $\begin{array}{l}\text { Emphasize } \\
\text { sustainability }\end{array}$ & $\begin{array}{c}\text { Emphasize anti-industry } \\
\text { motivations }\end{array}$ & $\begin{array}{l}\text { Do not focus on sustainability } \\
\text { and political concerns }\end{array}$ \\
\hline Recommendation 4 & $\begin{array}{l}\text { Avoid calculation and } \\
\text { references to money }\end{array}$ & $\begin{array}{l}\text { Minimize the } \\
\text { degree of calculations }\end{array}$ & Emphasize calculated benefits \\
\hline
\end{tabular}

Source: Habibi et al. (2017). 